\title{
The effects of muscle exercise and bed rest on $\left[{ }^{18} \mathrm{~F}\right]$ methylcholine PET/CT
}

\author{
Mark Roef • Wouter V. Vogel
}

Received: 30 July 2010 /Accepted: 1 October 2010 / Published online: 22 October 2010

(C) The Author(s) 2010. This article is published with open access at Springerlink.com

\begin{abstract}
Purpose This study evaluated the impact of limited and strenuous physical exercise on $\left[{ }^{18} \mathrm{~F}\right]$ methylcholine uptake in muscle.

Methods Ten consecutive patients participated, three of whom had strict bed rest, three were allowed to walk around and four performed strenuous single arm exercise by lifting a $7.5-\mathrm{kg}$ weight. $\left[{ }^{18} \mathrm{~F}\right]$ Methylcholine uptake was measured in the biceps and gluteus muscles on both sides. Results Strenuous exercise resulted in a $202 \%$ increase in $\left[{ }^{18} \mathrm{~F}\right]$ methylcholine uptake in the activated biceps muscle as well as a $112 \%$ increase in muscle groups used to retain body position. This resulted in asymmetrical images that were visually less easy to interpret. In walking patients there was a more limited increase in biceps $(45 \%)$ and gluteus (74\%) muscle uptake, without visually recognizable differences.

Conclusion Strenuous exercise may result in a considerable increase in $\left[{ }^{18} \mathrm{~F}\right]$ methylcholine uptake in muscle and should be avoided prior to imaging. Strict bed rest does not seem to be required. Tracer injection while resting on the scanner remains a safe approach.
\end{abstract}

Keywords Choline $\cdot\left[{ }^{18} \mathrm{~F}\right]$ Methylcholine $\cdot \mathrm{PET} / \mathrm{CT}$. Muscle exercise $\cdot$ Bed rest

\footnotetext{
M. Roef $\cdot$ W. V. Vogel $(\bowtie)$

Department of Nuclear Medicine, The Netherlands Cancer Institute - Antoni van Leeuwenhoek Hospital (NKI-AVL), Plesmanlaan 121,

1066 CX Amsterdam, The Netherlands

e-mail: w.vogel@nki.nl
}

\section{Introduction}

Imaging of choline metabolism with positron emission tomography (PET), with either $\left[{ }^{11} \mathrm{C}\right]$ - or $\left[{ }^{18} \mathrm{~F}\right]$-labelled choline, is increasingly used for detection, staging and surveillance of malignancies. $\left[{ }^{18} \mathrm{~F}\right]$ Methylcholine PET (choline PET) especially performs well in tumour types where fluorodeoxyglucose (FDG) uptake is generally limited, such as prostate cancer or differentiated breast cancer, and where tumour is surrounded by high physiological concentrations of FDG, such as primary brain tumours, brain metastases or prostate cancer [1-3].

Choline PET is a relatively new technique, and some uncertainties still exist with respect to the patient preparation that is needed to achieve an optimal biodistribution of labelled choline and a good image quality. For FDG PET there is extensive consensus about the requirements for patient preparation [4], including the duration of fasting time and the need for bed rest in order to minimize physiological uptake of FDG in muscle [5]. The issue of (bed) rest prior to choline PET scanning is more controversial. Most authors believe that at least $\left[{ }^{11} \mathrm{C}\right]$ choline is not hampered by muscle uptake, and they see no obvious reasons for bed rest [6]. As a consequence most publications on choline PET do not report anything about (bed) rest or the avoidance of strenuous exercise prior to scanning.

However, most centres currently use $\left[{ }^{18} \mathrm{~F}\right]$-labelled choline due to lack of an on-site cyclotron. $\left[{ }^{18} \mathrm{~F}\right]$ Methylcholine is chemically different from unmethylated choline, and it has a slightly altered biological behaviour in several aspects. This is illustrated by the rapid renal excretion of $\left[{ }^{18} \mathrm{~F}\right]$ methylcholine, which is absent in $\left[{ }^{11} \mathrm{C}\right]$ choline. 
Whether the uptake of $\left[{ }^{18} \mathrm{~F}\right]$ methylcholine in muscle depends on exercise, and if specific patient preparation is needed prior to imaging, is currently unknown.

In this study we evaluate the impact of limited and strenuous exercise on the uptake of $\left[{ }^{18} \mathrm{~F}\right]$ methylcholine in muscle, and we derive recommendations for optimal imaging in clinical practice.

\section{Materials and methods}

Ten consecutive patients were enrolled in this study, three of whom had strict (bed) rest, three were allowed to walk around and four performed strenuous single arm exercise. Resting patients were asked to avoid all physical exercise in the hours prior to imaging and were positioned on the PET/ CT scanner to rest from 5 min prior to administration of the tracer. Patients who were allowed to walk received no specific preparation instructions, and they were asked to walk a distance of about $50 \mathrm{~m}$ from the injection room to the scanner directly after administration of the tracer, after which the imaging procedure was immediately started. The arm exercise involved continuous lifting of a $7.5-\mathrm{kg}$ weight with the dominant arm with the patient sitting in an upright position, with an intravenous catheter in the other (relaxed) arm for tracer administration, whereafter the patient walked to the scanner. No specific dietary preparations were undertaken.

All patients were referred for choline PET/CT for restaging of recurrent prostate cancer, as detected by rising prostate-specific antigen (PSA) in serum after primary treatment. Patients were scheduled for a routine PET/CT scan for which they received on average $190 \mathrm{MBq}$ of $\left[{ }^{18} \mathrm{~F}\right]$ methylcholine as an intravenous injection. All images were acquired using an integrated PET/CT scanner with time-offlight capabilities (Gemini II, Philips Healthcare, Cleveland, $\mathrm{OH}, \mathrm{USA}$ ). PET images were acquired from mid-thigh to the base of the skull with attenuation correction based on lowdose CT within 5 min after administration of $\left[{ }^{18} \mathrm{~F}\right]$ methylcholine in order to limit renal excretion to the bladder. All patients were scanned in the prone position with the arms down to allow evaluation of the biceps muscles.

The generated images (PET, low-dose CT and fused $\mathrm{PET} / \mathrm{CT}$ ) were displayed using the OsiriX DICOM viewer in a Unix-based operating system (MAC OS X, Mac Pro, Apple) and were visually evaluated on the basis of twodimensional orthogonal reslicing. The uptake of $\left[{ }^{18} \mathrm{~F}\right]$ methylcholine [mean standardized uptake value $\left.\left(\mathrm{SUV}_{\text {mean }}\right)\right]$ in muscle was measured in a spacious and representative cylindrical region of interest with a thickness of 5 slices (4 $\mathrm{mm}$ each) in both biceps muscles and both gluteal muscles (see Fig. 1). The strict bed rest $\left[{ }^{18} \mathrm{~F}\right]$ methylcholine uptake was used as the gold standard to compare with the limited and strenuous physical exercise for semiquantification.

\section{Results}

All patients adhered to the preparations as described. The patients assigned to arm exercise reported it as "very demanding", and they all reached the maximum achievable muscle exercise after $3 \mathrm{~min}$. The PET/CT image quality was visually adequate in all cases. The results of muscle uptake quantification are listed in Table 1.

Fig. 1 Muscle uptake quantification. Transverse slices of $\left[{ }^{18} \mathrm{~F}\right]$ methylcholine PET (right) and image fusion with low-dose CT (left), showing the regions of interest used for evaluation of muscle uptake (green circles). Volumes with a thickness of 5 slices were delineated in the biceps (top) and gluteus maximus (bottom) muscles on both sides
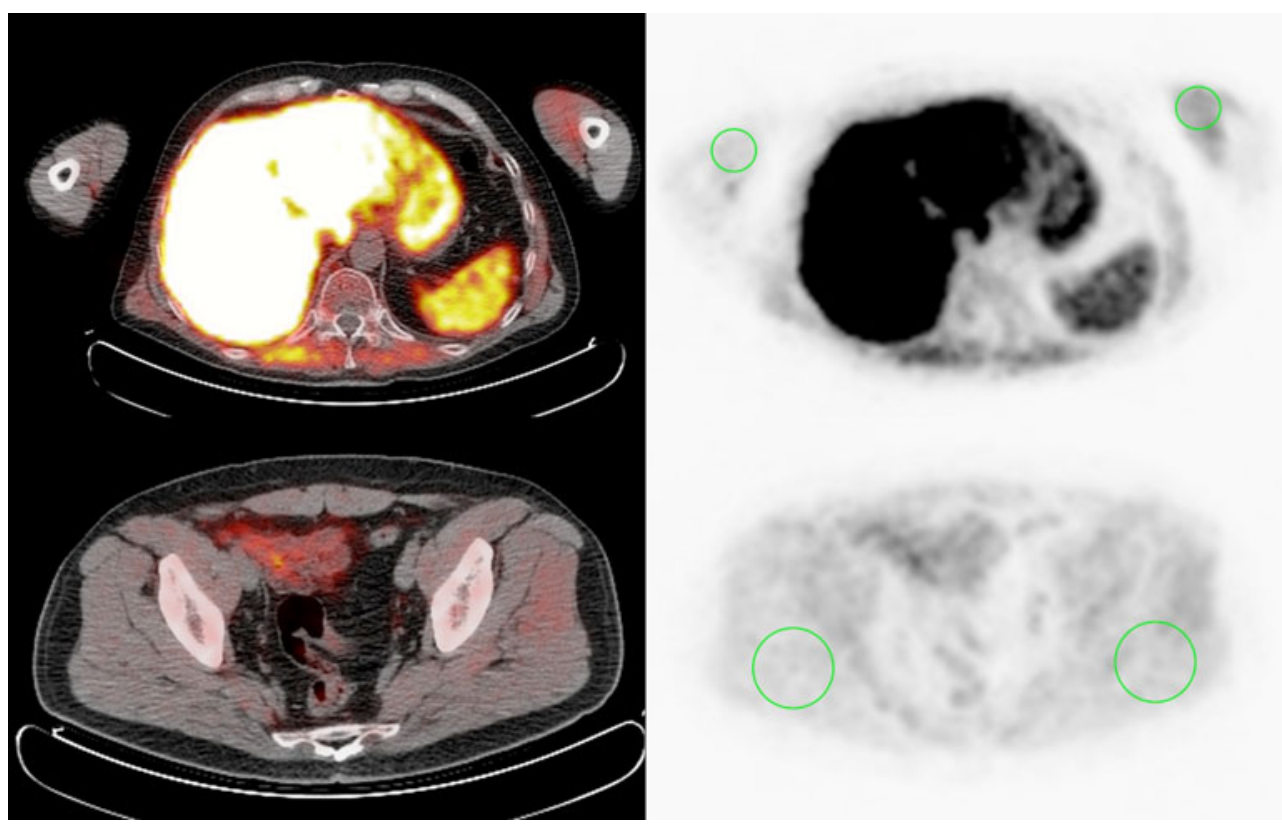
Table $1\left[{ }^{18} \mathrm{~F}\right]$ Methylcholine uptake in muscle $\left[{ }^{18} \mathrm{~F}\right]$ Methylcholine muscle uptake in resting, walking and exercising patients. Patients in the exercise group lifted a weight with their dominant arm

Domin. dominant arm side

\begin{tabular}{|c|c|c|c|c|c|c|c|c|}
\hline \multicolumn{3}{|l|}{ Patients } & \multicolumn{3}{|c|}{ Biceps $\left(\mathrm{SUV}_{\text {mean }}\right)$} & \multicolumn{3}{|c|}{ Gluteus ( $\left.\mathrm{SUV}_{\text {mean }}\right)$} \\
\hline Number & Age (years) & Domin. & Left & Right & Difference & Left & Right & Difference \\
\hline \multicolumn{9}{|l|}{ Resting } \\
\hline 1 & 74 & $\mathrm{R}$ & 0.98 & 0.84 & $17 \%$ & 0.76 & 0.79 & $4 \%$ \\
\hline 2 & 77 & $\mathrm{R}$ & 0.70 & 0.57 & $23 \%$ & 0.76 & 0.75 & $1 \%$ \\
\hline 3 & 58 & $\mathrm{R}$ & 0.70 & 0.91 & $12 \%$ & 0.64 & 0.72 & $11 \%$ \\
\hline \multicolumn{9}{|l|}{ Walking } \\
\hline 4 & 50 & $\mathrm{R}$ & 0.86 & 0.86 & $0 \%$ & 0.90 & 1.04 & $13 \%$ \\
\hline 5 & 61 & $\mathrm{R}$ & 1.60 & 1.37 & $17 \%$ & 1.63 & 1.99 & $18 \%$ \\
\hline 6 & 64 & $\mathrm{R}$ & 1.11 & 0.99 & $12 \%$ & 1.08 & 1.10 & $2 \%$ \\
\hline \multicolumn{9}{|l|}{ Exercise } \\
\hline 7 & 72 & $\mathrm{~L}$ & 2.27 & 1.10 & $106 \%$ & 2.09 & 1.33 & $57 \%$ \\
\hline 8 & 60 & $\mathrm{R}$ & 0.72 & 2.56 & $256 \%$ & 1.61 & 2.28 & $42 \%$ \\
\hline 9 & 65 & $\mathrm{R}$ & 0.50 & 1.94 & $288 \%$ & 0.43 & 1.53 & $256 \%$ \\
\hline 10 & 67 & $\mathrm{R}$ & 0.79 & 2.03 & $157 \%$ & 1.77 & 1.45 & $18 \%$ \\
\hline
\end{tabular}

Resting patients demonstrated variable uptake in biceps and gluteal muscles $\left(\mathrm{SUV}_{\text {mean }}\right.$ varied between 0.57 and 0.98 ), as well as differences between left and right in the same muscle group (up to $23 \%$ ). This indicates that differences in muscle uptake of $\left[{ }^{18} \mathrm{~F}\right]$ methylcholine within and between individual patients is physiological and is probably unavoidable to some extent.

Walking patients had a higher uptake in all evaluated muscle groups relative to resting patients, with the average $\mathrm{SUV}_{\text {mean }}$ of the biceps rising $45 \%$ and the gluteus increasing $74 \%$. However, this did not result in larger left- right differences or in visually recognizable differences in image quality or interpretation.

Strenuous exercise with one arm resulted in a considerable increase in $\left[{ }^{18} \mathrm{~F}\right]$ methylcholine uptake in the activated biceps muscle (Fig. 2), on average with $202 \%$ relative to the resting arm, and with $182 \%$ relative to the average biceps muscles of resting patients. At the same time it was visually apparent that the uptake of $\left[{ }^{18} \mathrm{~F}\right]$ methylcholine in muscles elsewhere in the body increased as well, depending on the muscle groups that the patient had activated during exercise to retain the body position and for breathing. As an example, the
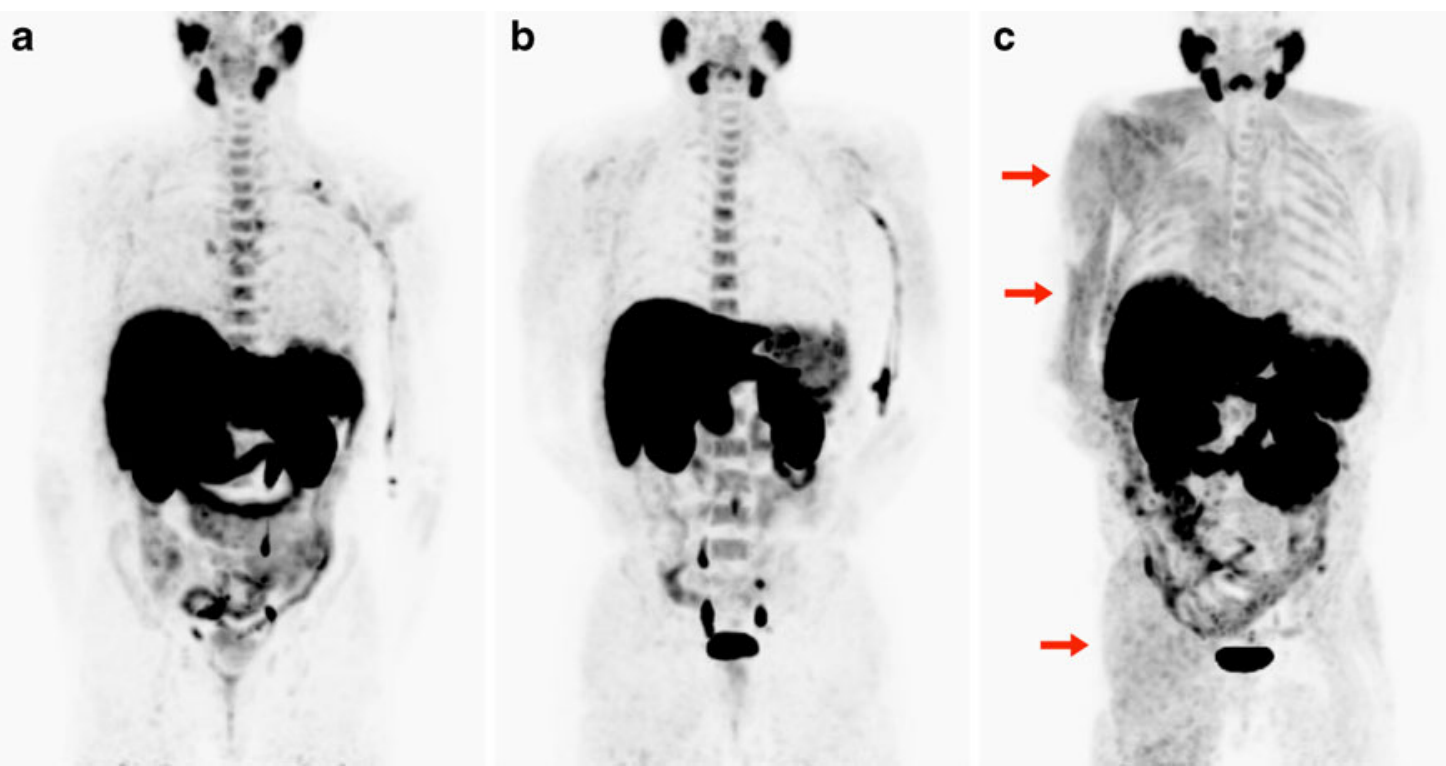

Fig. 2 The effect of strenuous arm exercise. Maximum intensity projections from three representative patients who received $\left[{ }^{18} \mathrm{~F}\right]$ methylcholine while already resting on the scanner (a), in a separate injection room followed by a short walk to the scanner (b) and while performing strenuous exercise with the right arm (c). Note the markedly increased uptake in the exercised biceps and the muscles used to retain body position (arrows) and intercostal muscles used for breathing 
gluteal muscles increased on average with $112 \%$ relative to resting patients, and also more than in walking patients.

\section{Discussion}

$\left[{ }^{18} \mathrm{~F}\right]$ Methylcholine PET/CT is rapidly gaining ground as a diagnostic tool, especially for prostate cancer, although the exact indications are still a topic of discussion. Good clinical value has been shown for restaging of biologically relapsed prostate cancer, including detection of local recurrence, regional lymph node metastases and distant metastases [7]. A good summary of valuable applications, including for brain lesions and hepatocellular carcinoma, is listed in a review by Mertens et al. [8]. However, the clinical value of choline PET can only be reproduced when a proper image quality is achieved. Our study demonstrates that strenuous muscle exercise can have a detrimental effect on choline PET imaging.

Little is known about choline uptake in muscle, either from tracer studies using $\left[{ }^{11} \mathrm{C}\right]$ - or $\left[{ }^{18} \mathrm{~F}\right]$-labelled choline. This study provides some new insights into the fate of $\left[{ }^{18} \mathrm{~F}\right]$ methylcholine in muscle and effects of exercise and resting on it. However, the current approach is limited by the low number of patients studied and does not allow for statistical evaluation. It is our intention just to highlight some mechanisms relevant for the uptake of $\left[{ }^{18} \mathrm{~F}\right]$ methylcholine in (normal) muscle and to derive suggestions for an imaging protocol that avoids negative impact on image quality.

Strenuous exercise results in a diffuse and considerable increase of $\left[{ }^{18} \mathrm{~F}\right]$ methylcholine uptake in the exercised muscle as well as in postural muscles involved in keeping the patient in an upright sitting position. This did result in asymmetrical and more "crowded" or "complicated" images. While we have no proof that this had any influence on the interpretation of the images with respect to the detection of prostate cancer lesions, we do classify the images as visually suboptimal. Limited exercise (walking) also resulted in a diffuse increase in uptake, but to a much lesser extent and with no noticeable influence on visual interpretation of the images.

The uptake of any tracer depends on tracer delivery (perfusion) and actual uptake in cells (transporters). These two processes will be involved in uptake of $\left[{ }^{18} \mathrm{~F}\right]$ methylcholine in muscle as well. Due to the observation that $\left[{ }^{18} \mathrm{~F}\right]$ methylcholine has a very fast biodistribution (within a few minutes), we think that muscle perfusion is an important mechanism in biodistribution of the tracer. Strenuous exercise is likely to result in grossly increased muscle perfusion, whereas limited exercise is not. Also the diffuse and regional character of the increased $\left[{ }^{18} \mathrm{~F}\right]$ methylcholine uptake after exercise agrees with the concept of muscle perfusion playing a role.
These observations may have an impact that goes beyond the uptake of $\left[{ }^{18} \mathrm{~F}\right]$ methylcholine in normal muscle alone. Local perfusion can also play an important role in choline uptake in tumour tissue, as has been suggested for liver hepatocellular carcinoma [9] and certain differentiated tumours of brain and lung $[10,11]$, or in infection and inflammation $[12,13]$. These effects may especially be of interest for imaging of tumours that are located within soft tissues, such as sarcomas, especially when limited tracer uptake is expected in the tumour. To our knowledge only $\left[{ }^{11} \mathrm{C}\right]$ choline has been used in PET imaging of musculoskeletal tumours [14, 15], and its relation to muscle perfusion has not been clarified. Our data suggest that, when using $\left[{ }^{18} \mathrm{~F}\right]$ methylcholine, avoiding physical exercise could be of value when attempting to image soft tissue sarcomas within muscle compartments or in comparable situations.

Avoiding muscle exercise is not the only factor that influences $\left[{ }^{18} \mathrm{~F}\right]$ methylcholine biodistribution and image interpretation. When patients are already positioned on the scanner during tracer administration the scan may be started more quickly after the injection. In combination with the absence of gravity in the direction of the bladder, this may further reduce the amount of tracer in the bladder during imaging relative to patients who have been walking. Therefore, tracer administration on the scanner remains a very good and safe approach. When this is not an option, we may state that walking a short distance does not result in serious changes in muscle uptake.

\section{Conclusion}

Strenuous exercise may result in a considerable increase in $\left[{ }^{18} \mathrm{~F}\right]$ methylcholine uptake in muscle, most likely due to increased local perfusion, and should be avoided shortly prior to imaging. However, this effect seems to be negligible when only walking a short distance, and thus strict bed rest seems not to be required during or after administration of $\left[{ }^{18} \mathrm{~F}\right]$ methylcholine. Tracer injection while resting on the scanner remains a very safe approach.

\section{Conflicts of interest None.}

Open Access This article is distributed under the terms of the Creative Commons Attribution Noncommercial License which permits any noncommercial use, distribution, and reproduction in any medium, provided the original author(s) and source are credited.

\section{References}

1. Chen W, Silverman DH. Advances in evaluation of primary brain tumors. Semin Nucl Med 2008;38:240-50. 
2. Langsteger W, Heinisch M, Fogelman I. The role of fluorodeoxyglucose, $18 \mathrm{~F}$-dihydroxyphenylalanine, $18 \mathrm{~F}$-choline, and $18 \mathrm{~F}$-fluoride in bone imaging with emphasis on prostate and breast. Semin Nucl Med 2006;36:73-92.

3. Jadvar H. FDG PET in prostate cancer. PET Clin 2009;4(2):155-61.

4. Boellaard R, O'Doherty MJ, Weber WA, Mottaghy FM, Lonsdale MN, Stroobants SG, et al. FDG PET and PET/CT: EANM procedure guidelines for tumour PET imaging: version 1.0. Eur J Nucl Med Mol Imaging 2010;37:181-200.

5. Abouzied MM, Crawford ES, Nabi HA.18F-FDG imaging: pitfalls and artifacts. J Nucl Med Technol 2005;33:145-55.

6. Groves AM, Win T, Haim SB, Ell PJ. Non-[18F]FDG PET in clinical oncology. Lancet Oncol 2007;8:822-30.

7. Fuccio C, Rubello D, Castellucci P, Marzola MC, Fanti S. Choline PET/CT for prostate cancer: main clinical applications. Eur J Radiol Epub 2010 Aug 25. doi:10.1016/j.ejrad.2010.07.023.

8. Mertens K, Slaets D, Lambert B, Acou M, De Vos F, Goethals I. PET with (18)F-labelled choline-based tracers for tumour imaging: a review of the literature. Eur J Nucl Med Mol Imaging 2010;37:2188-93.

9. Talbot JN, Gutman F, Fartoux L, Grange JD, Ganne N, Kerrou K, et al. PET/CT in patients with hepatocellular carcinoma using [(18)F]fluorocholine: preliminary comparison with [(18)F]FDG PET/CT. Eur J Nucl Med Mol Imaging 2006;33:1285-9.
10. Hara T, Kondo T, Hara T, Kosaka N. Use of 18F-choline and 11Ccholine as contrast agents in positron emission tomography imaging-guided stereotactic biopsy sampling of gliomas. J Neurosurg 2003;99:474-9.

11. Hara T, Inagaki K, Kosaka N, Morita T. Sensitive detection of mediastinal lymph node metastasis of lung cancer with $11 \mathrm{C}$ choline PET. J Nucl Med 2000;41:1507-13.

12. Le C, van de Weijer EP, Pos FJ, Vogel WV. Active inflammation in $18 \mathrm{~F}$-methylcholine PET/CT. Eur J Nucl Med Mol Imaging 2010;37:654-5.

13. Schillaci O, Calabria F, Tavolozza $\mathrm{M}$, Cicciò $\mathrm{C}$, Carlani $\mathrm{M}$, Caracciolo CR, et al. 18F-choline PET/CT physiological distribution and pitfalls in image interpretation: experience in 80 patients with prostate cancer. Nucl Med Commun 2010;31:39-45.

14. Yanagawa $\mathrm{T}$, Watanabe $\mathrm{H}$, Inoue $\mathrm{T}$, Ahmed AR, Tomiyoshi $\mathrm{K}$, Shinozaki T, et al. Carbon-11 choline positron emission tomography in musculoskeletal tumors: comparison with fluorine-18 fluorodeoxyglucose positron emission tomography. J Comput Assist Tomogr 2003;27:175-82.

15. Tateishi U, Yamaguchi U, Maeda T, Seki K, Terauchi T, Kawai A, et al. Staging performance of carbon-11 choline positron emission tomography/computed tomography in patients with bone and soft tissue sarcoma: comparison with conventional imaging. Cancer Sci00 2006;97:1125-8. 